\title{
LETTERS
}

\section{Could changes in pharmacotherapy peripregnancy contribute to the shift in means of suicide?}

The study by Grigoriadis and colleagues ${ }^{1}$ is on an important topic, because there is a major knowledge gap on the characteristics of perinatal women at risk of suicide, particularly in the year postpartum.

Interestingly, the authors found perinatal women were more likely to use more lethal methods of suicide (i.e., hanging) than those who were not perinatal, where overdose is known to be more common. ${ }^{1}$ Although these findings suggest a higher risk of suicide completion among perinatal women than for nonperinatal women at risk, I wonder what role access to psychotropic drugs contributed to these findings.

The decision to continue or discontinue medication peripregnancy remains a controversial one. My colleagues and I recently reported that as many as $38.6 \%$ and $22.5 \%$ of pregnant women who were receiving treatment with antidepressants stopped refilling their antidepressant prescription before the first and second trimesters, respectively, and only $9.4 \%$ continued treatment throughout their pregnancy. ${ }^{2}$ Further investigations into whether a shift in methods of suicide toward more lethal means is associated with accessibility to pharmacotherapy or being undertreated is of interest.

\section{Christine M. Leong PharmD}

Assistant Professor, College of Pharmacy, Apotex Centre, University of Manitoba, Winnipeg, Man.

- Cite as: CMAJ 2017 December 4;189:

E1497. doi: 10.1503/cmaj.733427

\section{References}

1. Grigoriadis S, Wilton AS, Kurdyak PA, et al. Perinatal suicide in Ontario, Canada: a 15-year populationbased study. CMAJ 2017;189:E1085-92.

2. Leong C, Raymond C, Chateau D, et al. Psychotropic drug use before, during, and after pregnancy: a population-based study in a Canadian cohort (2001-2013). Can J Psychiatry 2017;62:543-50.

Competing interests: None declared. 